\title{
14. Arithmetic using ADD, SUBTRACT, MULTIPLY and DIVIDE
}

Another method of doing arithmetic in COBOL is to use the commands: ADD, SUBTRACT, DIVIDE and MULTIPLY.

\section{ADD}

e.g. (1) ADD OVERTIME-PAY TO TOTAL-PAY.

OVERTIME-PAY is added to whatever number is already in TOTAL-PAY.

e.g. (2) ADD OVERTIME-PAY BASIC-PAY GIVING TOTAL-PAY.

(May also be written as

ADD OVERTIME-PAY TO BASIC PAY GIVING TOTAL-PAY).

The values of OVERTIME-PAY and BASIC-PAY are added and the result is stored in TOTAL-PAY without changing other items.

\section{SUBTRACT}

e.g. (1)SUBTRACT TAX FROM TOTAL-PAY.

TAX is deducted from whatever value is stored in TOTAL-PAY.

e.g. (2)SUBTRACT TAX FROM GROSS-PAY GIVING NET-PAY.

TAX is taken from GROSS-PAY and the answer stored in NET-PAY. (Note - the value of GROSS-PAY is not altered).

\section{MULTIPLY}

e.g. (1)MULTIPLY NUMBER1 BY NUMBER2.

The result will overwrite the contents of NUMBER2.

e.g. (2)MULTIPLY HOURLY-RATE BY 2 GIVING OVERTIME-RATE.

The result is stored in OVERTIME-RATE without changing other items.

\section{DIVIDE}

e.g. (1)DIVIDE NUMBER1 INTO NUMBER2.

The result overwrites NUMBER2.

e.g. (2)DIVIDE NUMBER-OF-STAFF INTO TOTAL-BONUS

$$
\text { GIVING STAFF-BONUS }
$$

e.g. (3)DIVIDE TOTAL-BONUS BY NUMBER-OF-STAFF

$$
\text { GIVING STAFF-BONUS }
$$

The result is placed in STAFF-BONUS without change to the other data items.

\section{DIVIDE ... REMAINDER}

The computer can also be asked to give a whole number and a remainder as the answer to a division if appropriate.

e.g. (1)DIVIDE NO-OF-CHILDREN INTO NO-OF SWEETS

GIVING NO-OF-SWEETS-PER-CHILD

REMAINDER SWEETS-LEFT-OVER.

e.g. (2)DIVIDE NO-OF-SWEETS BY NO-OF-CHILDREN

GIVING NO-OF-SWEETS-PER-CHILD

REMAINDER SWEETS LEFT-OVER.

Exercise

Repeat the questions in Lesson 13 using the commands ADD, SUBTRACT, MULTIPLY and DIVIDE instead of COMPUTE. 